\title{
BUTLER, J. (2004). UNDOING GENDER. NOVA YORQUE E LONDRES: ROUTLEDGE
}

\author{
Rita Himmel
}

Com a erosão da rigidez das estruturas modernas de organização social, as questões de identidade estão mais do que nunca no centro da vida em sociedade. A liquidez do mundo pós-moderno (Bauman, 2000) desfez muitas das armações que delimitavam a forma como nos apresentávamos ao mundo, abrindo possibilidades de identificação outrora impensáveis. Mas, existem ainda normas, de tal forma enraizadas, que não permitem viver este processo na sua totalidade. O género é o elemento mais paradigmático neste campo. Como poderemos chegar a uma verdadeira aceitação de cada humano como tal, para além da identidade de género? E se desfizéssemos a ideia de género como um fenómeno fixo e aceitássemos a narrativa de cada indivíduo como tal? Não estaríamos mais próximos da humanização de cada indivíduo, do seu reconhecimento, se olhássemos para a identidade de género como performativa?

Este é o argumento de Judith Butler que, na coleção de ensaios "Undoing Gender" (2004), sugere que desfaçamos o conceito de género, transpondo uma visão essencialista, permanente e binária, entre masculino e feminino, a qual remete para o não reconhecimento daqueles que excedem esta norma. Um contributo central para pensar as questões de identidade, de género e não só, no mundo pós-moderno, Butler nota que os que não se enquadram nas rígidas normas de género, simplesmente não são reconhecidos pela sua humanidade, e a transposição do género é o único caminho para combater esta situação.

O género é visto como um dos aspectos mais marcantes da nossa identidade, mas, se dizemos ser possuidores de uma sexualidade, esta não nos deveria possuir a nós, mas deveríamos ter a liberdade de a incorporar, sem que fossemos considerados menos reais por isso (Butler, 2004, p. 16). Como a autora questiona: porque é que consideramos que a origem da vida na diferença de sexualidade é um momento tão mais marcante da identidade de uma pessoa do que tantos outros, como forças sociais, condições económicas ou raciais? (Butler, 2004, p. 10).

Ao todo, para além da introdução, "Undoing Gender" inclui onze textos, cada um dos quais contribuindo para aprofundar esta mesma tese/interrogação, com uma densa base teórica, vinda desde a psicanálise à teoria queer. Na presente recensão serão abordados mais a fundo dois destes ensaios: um caso que ilustra a tensão entre género biológico e social e um outro que desconstrói a norma de género na sua configuração convencional. 


\section{GÉNERO ATRIBUÍDO VS GÉNERO CONSTRUÍDO}

"Doing Justice to Someone: Sex Reassignment and Allegories of Transsexuality" (Butler, 2004, pp. 57-74) é o texto que melhor ilustra empiricamente a necessidade de desfazer o género, com base na história de David Reimer, a pessoa no centro da disputa entre duas visões opostas: a construção social e a determinação biológica de género. Sem validar nem refutar qualquer uma das teses, Butler oferece uma terceira visão sobre o caso, que reflecte o argumento de que o género deve ser desfeito.

Nascido com cromossomas $X Y$, enquanto criança, o pénis de David ficou danificado após um acidente numa cirurgia. Os pais decidiram que David passaria a Brenda, após conhecerem as teorias de John Money, segundo o qual qualquer criança pode ser feliz sendo socializada e cirurgicamente adaptada segundo um determinado género (Butler, 2004, 59). Quando Brenda começou a querer comprar brinquedos de rapaz, a recusar-se a urinar sentada, a tomar estrogénio e a ser submetida a cirurgia, os psiquiatras locais consideraram que a socialização de David como Brenda tinha sido um erro. Foi então que Milton Diamond, um investigador que defende a origem hormonal da identidade de género, tomou conta do caso. Aos 14 anos, Brenda passou a viver como David, recebendo tratamento hormonal e alterações cirúrgicas (Butler, 2004, p. 60). Na primeira fase, a vida de David serviu para justificar a teoria de que a identidade de género pode ser social e cirurgicamente construída, que é maleável e neutra na infância, apesar de registos de entrevistas não publicados mostrarem que a adaptação não era pacífica. $\mathrm{Na}$ segunda fase, serviu para sustentar a tese de que cada pessoa tem uma identidade sexual original, uma verdade interna imutável (Butler, 2004, p. 62).

Ou seja, toda a discussão foi sempre colocada dentro desta dicotomia entre social e biológico, e, mais profundamente, entre feminino e masculino, sendo que a possibilidade de existência fora dessa estrutura não foi considerada. Butler sugere um terceiro olhar, partilhado pelo movimento intersexo: "O objectivo é tentar imaginar um mundo no qual indivíduos com atributos genitais mistos possam ser aceites e amados sem que tenham que ser transformados numa versão de género mais socialmente coerente ou normativa" (Butler, 2004, pp. 64-65).

A grelha para o questionamento da humanidade deve ser a do auto-conhecimento (Butler, 2004, p. 67), mas este é sempre moldado pela linguagem que o permite. O auto-conhecimento de David foi feito num contexto fora do comum: de forte monitorização e avaliação em comparação com um modelo de feminidade e masculinidade. A sua auto-definição é feita perante uma audiência e com base na linguagem pré-existente que foi moldada pelas normas vigentes (Butler, 2004, p. 67). Por exemplo, o facto de Brenda querer brincar com determinados brinquedos foi imediatamente interpretado pelo próprio como um desvio da norma do que significa ser rapariga (Butler, 2004, p. 70)

A narrativa de David é um exemplo extremo de como o género é um eixo tão central da identidade humana, que é sempre visto como necessário, seja com base em justificações biológicas ou sociais, que esta incorpore um dos polos do binário feminino/ masculino. Se houvesse a possibilidade de David verdadeiramente se auto-identificar, construir a sua narrativa para além da questão de género, não seria a possibilidade de reconhecimento maior? 


\section{A PATOLOGIZAÇÃo DA IDENTIDAdE}

Se o ensaio sobre David demonstra a realidade concreta das normas de género, em "Undiagnosing Gender" (Butler, 2004, pp. 75-101) Butler foca-se nas normas construídas formalmente. Neste ensaio, Butler discute potencialidades de empoderamento e opressão que a inclusão do transtorno de identidade de género no DSM-IV, o manual de distúrbios mentais, proporciona.

A autora identifica a tensão entre os argumentos a favor e contra o diagnóstico como inseridas no paradoxo da autonomia. Por um lado, a manutenção do diagnóstico permite o acesso a condições seguras para as pessoas com menos possibilidades para fazerem a transição. Por outro lado, ser diagnosticado com transtorno de identidade de género é ser considerado "estar doente, enfermo, errado, estragado, anormal e sofrer uma certa estigmatização como consequência da própria existência do diagnóstico" (Butler, 2004, p. 76).

O diagnóstico pode permitir o empoderamento, contribuindo para a autonomia da pessoa ao possibilitar que esta faça a transição nos seus termos e ao ser utilizado estrategicamente, enquanto o argumento da patologização é rejeitado. Por outro lado, limita esta autonomia ao diagnosticar a pessoa, ao submetê-la a um processo e linguagem marcados pelas normas de género.

Mais do que isso, o diagnóstico presume uma identidade fixa, é necessário provar-se que se quis viver como o outro género durante um longo período de tempo, assim como ter um plano de vida para viver de acordo com esse género (Butler, 2004, p. 81).

Resumidamente, é uma questão de como se olha para o conceito de autonomia. Os argumentos a favor do diagnóstico vêem-no como potencialmente empoderador da autonomia individual, uma vez que pode ser utilizado como instrumento. Contra o diagnóstico, está o argumento de que pode limitar a autonomia dos que sofrem por causa da patologização, fomentando o estigma. Sem ele, a vida prática de muitas pessoas é dificultada. Com ele, é utilizada uma linguagem na qual as pessoas não acreditam, fazendo com que as questões que devem ser discutidas não sejam levantadas (Butler, 2004, p. 91).

O diagnóstico levanta uma série de questões sobre como se estabelece este transtorno, principalmente nas crianças: rapazes que brincam com brinquedos femininos, raparigas que gostam de vestir roupas masculinas. "Imagina que cada indivíduo tem uma relação com o "sexo atribuído" e que esta relação ou é de desconforto e angústia ou de conforto e de estar em paz" (Butler, 2004, p. 97). Ao mesmo tempo, este género é medido através de objectos culturais: roupas, brinquedos etc.

Para além dos objectos sociais, há os elementos corporais. A questão da cirurgia coloca-se no centro da performatividade, uma vez que o cultivar de características sexuais secundárias dentro das normas é aceite como uma escolha não patologizada. $O$ que prova que os indicadores corporais sexuais são meios culturais, uma vez que uma mulher não é considerada como sofrendo de uma patologia se quiser aumentar o peito, para se tornar o mais feminina: "o sexo é tornado perceptível através de signos que indicam como o mesmo deve ser lido e compreendido" (Butler, 2004, p. 87).

Butler conclui que vivemos um paradoxo de autonomia. O ideal seria existir um contexto que permitisse às pessoas aceder à transição sem ser necessário patologizar. 
Mas, no contexto actual, o diagnóstico pode ser necessário para alguns, obrigando a viver neste paradoxo, de "ser desfeitos para nos podermos fazer" (Butler, 2004, p. 100).

Desde a publicação de "Undoing Gender", o transtorno de identidade de género foi substituído por "disfunção de género" na versão revista do DSM, DSM-5, publicado em 2013. Esta suavização linguística é justificada pela vontade de evitar o estigma (APA, 2013), ao não ser visto como um distúrbio mental. Apesar de afirmar evitar o estigma, este diagnóstico mantém uma característica essencial que dificulta a performatividade: a visão de género como um fenómeno relativamente permanente (Butler, 2004, p. 81).

\section{IDENTIDADE E RECONHECIMENTO}

O estudo da identidade está no coração dos Estudos Culturais. Com as alterações que o conceito tem sofrido à medida que os pressupostos que o sustentavam foram sendo questionados, torna-se necessário desfazer e refazer a forma como pensamos a identidade. A diferença de género, neste contexto, tem uma função paradigmática relativamente a outros eixos de exclusão (Hall, 1996, p. 15), e, portanto, pode ser a chave para repensar todo o conceito. Para Stuart Hall, a visão de identidade como performance é um importante passo para ultrapassar o impasse da incapacidade de construir uma ponte entre as estruturas discursivas da identidade que é imposta e a capacidade do indivíduo de se identificar.

O contributo de Butler é fulcral, não apenas no campo dos estudos de género e nos Estudos Culturais. Mais do que académico, é um contributo humano e político necessário e urgente para a promoção de um verdadeiro reconhecimento inclusivo, uma vez que procura estabelecer uma ponte sólida entre a possibilidade de autonomia individual e o reconhecimento social da humanidade de cada um.

\section{REFERÊNCIAS}

American Psychiatric Association. (2013). Gender dysphoria. Acedido em APA DSM-5 http://www.dsm5.org/ documents/gender\%2odysphoria\%2ofact\%2osheet.pdf

Bauman, Z. (2000). Liquid modernity. Cambridge: Polity Press.

Butler, J. (September - December de 2009). Performativity, precarity and sexual politics. Revista de Antropología Iberoamericana, 4, i-xiii.

Butler, J. (2004). Undoing gender. Nova Yorque e Londres: Routledge.

Hall, S. (1996). Introduction: who needs 'Identity'? In e. S. Gay, Questions of Cultural Identity (pp. 1-17). Londres: Sage.

Rita Himmel é doutoranda do Programa Doutoral em Estudos Culturais das Universidades de Aveiro e do Minho, onde actualmente desenvolve um projecto de investigação sob o tema das identidades, representações e media. Licenciada em Ciências da Comunicação pela Faculdade de Letras da Universidade do Porto e Mestre em Relações 
Internacionais pela Universidade de Amesterdão, tem como interesses científicos, para além do actual tema de investigação, questões de Direitos Humanos, soberania alimentar e movimentos transnacionais. Profissionalmente, tem experiência na área da Comunicação e do Jornalismo, em entidades como o jornal Público, a emissora Deutsche Welle e o Gabinete de Informação do Parlamento Europeu.

E-mail: rita.himmel@ua.pt

Universidade de Aveiro / Universidade do Minho Instituto de Ciências Sociais, Campus de Gualtar 4710-057 Braga

* Submetido: 16-02-2015

* Aceite: 20-04-2015 